\section{PUBLICACIONES EN LA CIUDAD DEL SABER}

La Universidad de Alcalá de Henares, centro de reconocida y secular incidencia en el panorama académico tanto europeo como americano, ofrece una biografía en su vinculación con la ciudad que le acogiera históricamente, lo que justifica lo adecuado de su papel como sede de la $\mathrm{V}$ Conferencia Internacional sobre Conservación de Centros Históricos y Patrimonio Edificado Iberoamericano bajo el lema "La Ciudad del saber. Ciudad, Universidad y Utopía" que se llevó a cabo entre el 25 y el 31 de julio de 1993, año en que se cumplen los setecientos años del inicio de la actividad académica en la ciudad complutense con los Estudios Generales de Sancho IV.

El tema central fue la Ciudad. La Ciudad como paradigma cultural, como categoría universal histórica, como problemática actual, como proyecto de futuro, todo ello contemplado bajo un amplio punto de vista multidisciplinar, a través del cual permitió evaluar la lógica que ha caracterizado el desarrollo del espacio académico. Simultáneamente con el Congreso se desarrollaron actividades afines paralelas, como los Cuatro Talleres de Arquitectura, en los que se presentaron, discutieron y se terminaron de desarrollar los ejercicios iniciados dos meses antes a la celebración del mismo y que fueron dirigidos por prestigiosos profesionales iberoamericanos y europeos (Dieste, Salmona, Lombardi, Siza). Otra de las actividades destacadas fue la exposición de revistas de arquitectura, ingeniería, diseño y construcción, llegadas de todos los países iberoamericanos y España, exposición cuyo catalogo ofrece una tarea inédita dentro del campo de la bibliografía conjunta en Iberoamérica: un registro sistemático por medio de una ficha técnica con su comentario bibliográfico de más de doscientas publicaciones periódicas de ambos continentes que están vigentes en la actualidad.

El trabajo, coordinado desde España por el Instituto Español de Arquitectura de la Universidad de Alcalá, ha contado con dos equipos, uno en Iberoamérica coordinado por el arquitecto Ramón Gutiérrez y otro en España a cargo del arquitecto Marcelo Martín.

Las revistas de arquitectura, ingeniería, diseño y construcción conforman un caleidoscopio panorama del acontecer cultural en la materia de ambas orillas, y que sirve, no ya para comparar, sino más bien para difundir y estructurar un conocimiento mutuo de intereses, objetivos y actuaciones profesionales de un colectivo detrás del cual existen trescientos millones de hispanohablantes con reconocido raíces culturales comunes.

Esta iniciativa tiene antecedentes. Los encuentros de Revistas Latinoamericanas de Arquitectura, que ya se han llevado a cabo desde 1968 en coincidencia con los cinco SAL (Seminarios de Arquitectura Latinoamericana) realizados en Buenos Aires, Manizales, Santiago de Chile y Caracas, y la Bibliografía de Arte y Arquitectura editada por la Consejería Obras Públicas y Transportes de la Junta de Andalucía, en el marco del Encuentro Andalucía-América que tuviera lugar en Buenos Aires en 1990. Este último trabajo, también realizado por dos equipos de americanos y españoles dejó pendiente el desafío que hoy se materializa, el de acercar y difundir la edición de revistas profesionales de la arquitectura y afines a través de un trabajo de fichado y catalogación sistemático.

Conscientes de la magnitud de la tarea, los responsables del trabajo saben que esta no ha acabado, que necesariamente deberá someterse a un completamiento cuyo objetivo final será una edición posterior de este mismo catálogo, donde se hayan incorporado las posibles ausencias que la lógica premura del primer esfuerzo hubiera producido. La exposición y el catálogo fueron, sin duda, un digno aporte a las seguramente positivas consecuencias de esta $V$ Conferencia del Consejo Académico Iberoamericano y un claro logro del objetivo por este Consejo sostenido: impulsar la realización de las investigaciones y publicaciones conjuntas como forma de estrechar la cooperación y el conocimiento. En nuestro próximo número editaremos las conclusiones de esta $\mathrm{V}$ Conferencia.

\section{REUNIÓN DE LA COMISIÓN DE TRABAJO INTERMEDITERRÁNEA}

Se celebró en Mayo del 93, en la ciudad de Rodas, con la asistencia de representantes de regiones mediterráneas de España, Italia, Francia, Grecia y Portugal, la IV Reunión de la Comisión de Trabajo Intermediterránea. La Declaración final llama la atención de la Comisión, del Consejo del Parlamento Europeo sobre cinco puntos resumen de la IV Reunión donde se incluye la prioridad que se ha de dar a la protección del medio ambiente mediterráneo, instrumento esencial de todo desarrollo, de las culturas tradicionales y del patrimonio, excesivamente descuidados en el pasado por los programas y acciones comunitarias.

Junto con la Declaración Final se aprobaron una serie de Resoluciones entre las que destacamos:

- Carta del Paisaje Mediterráneo. Esta Resolución, presentada por Andalucía y aprobada por unanimidad, manifiesta el apoyo de la Comisión Intermediterránea a la iniciativa de redactar una Carta del Paisaje Mediterráneo que, en el marco de los objetivos del Consejo de Europa, y de las demás instituciones europeas: defina los valores patrimoniales y sociales de nuestro paisaje y su aplicación: haga un diagnóstico de su estado actual en relación con los procesos económicos, demográficos y ecológicos, fije los objetivos de una política de conservación y gestión $y$, finalmente, sea la base de actuaciones específicas, culturales y políticas inmediatas.

- Encuentro de las culturas mediterráneas. Esta Resolución, también presentada por Andalucía y aprobada igualmente por unanimidad, señala que la IV Comisión Intermediterránea se congratula de la celebración del Primer Encuentro de las Culturas Mediterráneas, celebrado en Almería en octubre de 1992 y apoya la continuación de los mismos en otras regiones. Asimismo, estima necesario favorecer la formación de grupos de trabajos para el estudio de las competencias culturales de cada región, la inventarización de artesanías, ceremonias y fiestas tradicionales y los modos de proyectar todo ello en las demás regiones de Europa y en todo el mundo. Por último, apoya la decisión de Baleares de organizar los II Encuentros.

\section{POR FILIGRANAS}

Se está llevando a cabo en el Instituto de Conservación y Restauración de Bienes Culturales, en la Subdirección General de Información e Investigación, un proyecto de investigación, financiado por el plan I+D del Consejo de Universidades, cuyo título es: "Filigranas papeleras. Creación de una base de datos al servicio de Archivos, Bibliotecas, Museos y Centros de Documentación".

Como es de todos sabido la filigrana es un elemento utilísimo para la datación de documentos y a través de ella podemos saber dónde y cuándo un papel fue hecho.

En este inventario queremos recoger y completar la callada labor realizada por los numerosos investigadores que han trabajado en España sobre este tema y que, por diversos motivos permanece inédita, o que, a pesar de estar publicada, resulta de muy difícil consulta.

Simultáneamente a esta labor estamos recogiendo filigranas de las zonas geográficas menos estudiadas y para ello en el caso de Andalucía Oriental contamos con la colaboración de José Carlos R. Balmaceda ex jefe de división de Conservación y Restauración de documentos del Senado de la Nación Argentina, que desinteresadamente está realizando un interesante trabajo que posteriormente queremos completar con filigranas tomadas de la documentación de Archivos de Argentina entre otros países americanos.

El estudio de papel y sus filigranas en Andalucía Oriental lo hemos iniciado en el Archivo Histórico Provincial de Málaga a cuya directora Sra. Enriqueta Durán queremos agradecer desde aquí su colaboración.

M. del Carmen Hidalgo Brinquis Investigador Responsable del Proyecto 